\title{
Analysis of isokinetic knee strength in soccer players in terms of selected parameters
}

\author{
Yılmaz A.K. ${ }^{1 \mathrm{ABCDE}}$, Kabadayı M. ${ }^{1 \mathrm{ABCDE}}$, Bostancı Ö. ${ }^{2 \mathrm{ABCDE}}$, Özdal M. ${ }^{1 \mathrm{ABCDE}}$, Mayda M.H. ${ }^{1 \mathrm{ABCDE}}$ \\ ${ }^{1}$ Faculty of Sports Sciences, Ondokuz Mayıs University, Turkey \\ ${ }^{2}$ Faculty Physical Education and Sport, Gaziantep University, Turkey
}

Authors' Contribution: A - Study design; B - Data collection; C - Statistical analysis; D - Manuscript Preparation; E - Funds Collection.

\begin{abstract}
Purpose: $\quad$ The aim of study is to analyse isokinetic knee strength in soccer players in terms of selected parameters.

Material: $\quad$ A total of 30 subjects, 15 soccer players and 15 controls, were included in the study. Isokinetic knee strength measurements at angular speeds of $60^{\circ} \mathrm{sec}^{-1}, 180^{\circ} \mathrm{sec}^{-1}$ and $240^{\circ} \mathrm{sec}^{-1}$ and pro-agility tests were conducted on the subjects. A body analyser was used for height, weight and body mass indexes (BMI) values. The training ages of the subjects and the positions of the soccer player group were recorded on personal information forms.

Results: $\quad$ When the agility parameters were compared between football and control groups, a statistical difference was found in favour of the soccer player group $(p<0.05)$. When the effects of body composition and isokinetic knee strength on agility were analysed, negative significant correlation was found between weight and agility, BMI and agility and $240^{\circ}$ right knee extension strength and agility $(p<0.05)$. When the positions of soccer players and isokinetic knee strengths were compared, significance was found between $60^{\circ}$ right extension strength of defenders and midfielders and $60^{\circ}$ left extension-flexion strengths of defenders and midfielders and forwards in favour of defenders $(p>0.05)$.

Conclusions: In conclusion, it was found that isokinetic knee strength did not have an influence on agility in low angular speeds, except for $240^{\circ} \mathrm{sec}^{-1}$ right extension. According to positions, as the isokinetic knee strength of defenders decreased, they showed higher results when compared with other positions.

Keywords: isokinetic, knee, strength, soccer player, agility.
\end{abstract}

\section{Introduction}

Football is a game that requires physical competence as well as top-level motor skills such as technicaltactical agility and speed because of the high number and intensity of matches it involves [1,2]. Additionally, player position [3], the league that the player is in, and even the style of the game played [4] have significant effects on a soccer player's muscle profile. Studies have shown that soccer players cover long distances during a match and the distance they cover differs according to the levels and positions they play in $[5,6]$. It is known that midfielders and defenders cover longer distances when compared with forwards, and offensive players are more exposed to moves that require slipping, jumping and man-to-man offence [7]. The basis of all these specific features is muscle strength [8].

Studies have shown that lower extremity strength has great significance of these specific moves in football like a strength [8], speed [9], acceleration [10], endurance [11]. In addition, isokinetic knee strength has been found to influence the speed of kicking the ball [12]. Lower extremity strength, which could previously be found with squat and vertical jump tests in general, can now be measured more objectively with isokinetic dynamometers and - thanks to dynamometers - dominant and nondominant foot strengths can also be examined separately $[13,14]$. Determining the lower extremity strength capacity of a player has great importance with respect to preventing injuries and determining the intensity of

(c) Yılmaz A.K., Kabadayı M., Bostancı Ö., Özdal M., Mayda M.H., 2019 doi:10.15561/20755279.2019.0408 training. Isokinetic strength values have also been found to be high as age and league levels increase $[15,16]$. When studies conducted on soccer players were examined, it was found that dominant and non-dominant foot strengths generally did not show significant correlations [17]; however, low levels of significant differences were found as angular speed increased $[18,19]$.

The purpose of study is to analyse the effects of isokinetic knee strength of soccer players on selected physical parameters and motoric features and to compare all these parameters with respect to player positions. The subjects consisted of 15 soccer players in the Turkish Football Federation Regional Amateur League. The data were collected to compare isokinetic knee strengths of soccer players in terms of selected physical parameters, agility and positions, which is the hypothesis of the study.

\section{Material and methods}

\section{Participants}

The study included 15 soccer players (football group) who were trained five days a week for at least 2 hours each day in amateur leagues and 15 individuals (control group) who had a training history of 2-3 years out of football and who were not actively doing sports (Table 1). The study protocol was approved by the Ethics Committee for Ondokuz Mayıs University. (B.30.2.ODM.0.20.08/1596).

Research Design

The subjects were tested in a laboratory twice and indoor sports hall once. At the first laboratory visit, the subjects were informed about the test protocols, and their 
heights, weights and body mass indexes (BMI) were measured. At the second one, the subjects' isokinetic knee strength measurements were done (at $60^{\circ} \mathrm{sec}^{-1}, 180^{\circ}$ $\mathrm{sec}^{-1}$ and $240^{\circ} \mathrm{sec}^{-1}$ angular speeds, in order to find the peak torque values). Pro-agility tests were conducted in the indoor sports hall. Before the test started, the subjects were informed about the test and they were asked to perform the test with maximum effort. The subjects were warned about not doing any exercise or physical activity before the all test.

Warm-up procedure

Before the tests, the subjects undertook 5 minutes of low intensity aerobic run and 10 minutes of dynamic and static stretching of lower extremity muscles for general warm-up [20].

\section{Determination of descriptive information}

A Gaia 359 Plus BodyPass analyser was used to find out the height, weight and BMI parameters of the subjects. Before the measurements, the device was introduced to all the subjects and they were asked to stay as quiet and as immobile as possible during the test. An individual demonstrated the test on the analyser to help the subjects understand it. The subjects stood on the analyser with bare feet, wearing a t-shirt and shorts, and their height $(\mathrm{cm})$, weight $(\mathrm{kg})$ and BMI values were recorded. The subjects' age, position and training ages were obtained from the personal information form given to subjects.

Determination of isokinetic knee strength

The peak torque angular speeds that the subjects were to show in knee extension and flexion moves were determined as $60^{\circ} \mathrm{sec}^{-1}, 180^{\circ} \mathrm{sec}^{-1}$ and $240^{\circ} \mathrm{sec}^{-1}$. The tests were conducted with computer controlled isokinetic dynamometer (Humac Norm Testing and Rehabilitation System, CSMI, USA). For each test at the determined angles, the subjects were warned verbally to take into consideration the resting intervals in line with the fixed protocol of the dynamometer.

With the determination of resting intervals, subjects were asked to show five maximum efforts and the highest values displayed during five tries of all angular speeds were accepted as peak torque values. In order to ensure the adaptation of the subjects and to protect them from injuries, three practice repetitions of all angular speeds were made before the test and the test was started after 30 seconds of rest. During the whole test, each subject was encouraged about basic push/pull and the number of remaining repetitions and loud verbal encouragement were given continuously to help the peak torque (PT) values of the subjects to be the highest level. Before starting the test, all the subjects were asked to use their knee strength in the maximal level for a positive test and to get maximal results [21]. In all angular speeds, PT values were recorded as Newton $(\mathrm{Nm})$. Before isokinetic knee strength, isokinetic dynamometer was calibrated as advised by CSMI (2003).

Pro-agility test

A pro-agility test, also known as a 20 yard (18.2982 $\mathrm{m})$ sprint, was conducted on the subjects. The test area was adjusted by placing pointers $4.57 \mathrm{~m}$ left and $4.57 \mathrm{~m}$ right of the start line. Tagheuer HL-232 photocell doors, which can record percentiles of a second, were placed at the start line and the area in which the study would be conducted was defined with pointers. The data from the photocell was directly transferred to the computer with a Tagheuer CP-540. After the photocell system was tested, the subjects were taken to the area. They were told that the participant had to be in place at the start line and, when he was ready, to touch the pointer on the right and then the one on the left at the same time with hands and feet and to end the test by passing the start line. After being shown how to do the test, each subject had to do a trial test three times and received feedback. At the beginning, the subjects to be tested were determined randomly and the test was predicted to be completed according to that order. All the subjects were tested three times with intervals of 1 minute. The subjects were given feedback to help them get the best results. The subjects' best times from these three tests were recorded in seconds (sec) and the test was concluded.

Statistical Analysis.

SPSS for Windows (version 16.0, 2008, SPSS Inc., Chicago, Illinois, USA) was used for statistical analysis. The data were presented as mean and standard deviation. Normal distribution of data was tested using the ShapiroWilk's test and a Levene test was used to test homogeneity. An independent t-test was applied in the comparison of two groups. A Pearson correlation was performed to control the association between variables. Statistical results were assessed within the $95 \%$ confidence interval and a $\mathrm{p}<0.05$ level of significance.

\section{Results}

Table 1 shows the descriptive information of the study. There were no significant difference between the soccer

Table 1. Comparison of descriptive information of the football and control groups

\begin{tabular}{|c|c|c|c|c|c|c|}
\hline Variable & Group & $\mathbf{N}$ & Mean & Std. Dev. & $\mathbf{t}$ & $\mathbf{p}$ \\
\hline Age & Soccer & 15 & 22.80 & 2.14 & \multirow{2}{*}{1.813} & \multirow{2}{*}{0.082} \\
\hline (years) & Control & 15 & 21.60 & 1.40 & & \\
\hline Height & Soccer & 15 & 177.00 & 4.90 & \multirow{2}{*}{0.645} & \multirow{2}{*}{0.524} \\
\hline$(\mathrm{cm})$ & Control & 15 & 175.73 & 5.81 & & \\
\hline Weight & Soccer & 15 & 75.95 & 6.91 & \multirow{2}{*}{1.601} & \multirow{2}{*}{0.123} \\
\hline (kg) & Control & 15 & 72.63 & 4.07 & & \\
\hline BMI & Soccer & 15 & 24.22 & 1.61 & \multirow{2}{*}{1.016} & \multirow{2}{*}{0.319} \\
\hline$\left(\mathrm{kg} / \mathrm{m}^{2}\right)$ & Control & 15 & 23.57 & 1.84 & & \\
\hline
\end{tabular}


players and the control group with respect to descriptive information $(p>0.05)$.

When the agility parameters were compared between groups (Table 2), a statistically significant difference was determined in favour of the soccer group $(\mathrm{p}<0.05)$.

There were no differences right and left isokinetic knee extension and flexion strength parameters between the groups ( $>>0,05)$, (Table 3$)$.

In the correlation test conducted to find out the effect of soccer players' body composition and isokinetic knee strength on agility (Table 4). When the pro-agility test time improved, weight, BMI and $240^{\circ}$ right knee extension strength increase $(\mathrm{p}<0.05)$.

Table 5 examines the correlation between soccer players' positions and their descriptive information, agility and isokinetic knee strength rates. When the results were analysed, significant differences were found as follows: in weight between defenders and midfielders and the control group; in training age between all positions and the control group; in agility test between defenders and the control group; in $60^{\circ}$ right extension strength between defenders and midfielders and also the control group and midfielders; in $60^{\circ}$ left extension strength between defenders and midfielders and forwards and also between the control group and midfielders and forwards; and in $60^{\circ}$ left flexion strength between defenders and forward midfielders and also the control group and forwards $(\mathrm{p}<$ $0.05)$.

\section{Discussion}

Football is a sport based on aerobic-anaerobic strength and muscle strength and at the same time it requires a toplevel display of motoric features. In the studies conducted, the most commonly used moves include kick the ball, jumping and running, and all these moves are reported to be directly associated with knee joint muscles [22, 23].

In our study, when isokinetic knee strengths were examined, no significant difference was found between the two groups $(p>0.05)$. When compared with the literature, the results were found to be similar to results

Table 2. Comparison of pro-agility parameters of football and the control group

\begin{tabular}{lllllll}
\hline Variable & Group & $\mathbf{N}$ & Mean & Std. Deviation & $\mathbf{t}$ & $\mathbf{p}$ \\
\hline \multirow{2}{*}{ Pro-Agility (sec) } & Soccer & 15 & 4,70 & 0,22 & \multirow{2}{*}{$\mathbf{2 , 1 8 9}$} & \multirow{2}{*}{$\mathbf{0 , 0 3 7 ^ { * }}$} \\
& Control & 15 & 4,89 & 0,26 & & \\
\hline
\end{tabular}

${ }^{*} p<0,05$

Table 3. Comparison of isokinetic knee strength parameters of the football and the control group

\begin{tabular}{|c|c|c|c|c|c|c|}
\hline Variable & Group & $\mathbf{N}$ & Mean & Std. Deviation & $\mathrm{t}$ & $\mathbf{p}$ \\
\hline \multirow{2}{*}{$\begin{array}{l}\text { 60o Right knee Ext. } \\
\text { Strength }(\mathrm{nm})\end{array}$} & Soccer & 15 & 165.00 & 24.83 & \multirow{2}{*}{0.779} & \multirow{2}{*}{0.445} \\
\hline & Control & 15 & 154.40 & 46.51 & & \\
\hline \multirow{2}{*}{$\begin{array}{l}60 \text { o Right knee Flex. } \\
\text { Strength }(\mathrm{nm})\end{array}$} & Soccer & 15 & 105.60 & 17.70 & \multirow{2}{*}{1.272} & \multirow{2}{*}{0.214} \\
\hline & Control & 15 & 94.93 & 27.22 & & \\
\hline \multirow{2}{*}{$\begin{array}{l}60 \text { - Left knee Ext. } \\
\text { Strength }(\mathrm{nm})\end{array}$} & Soccer I & 15 & 169.73 & 29.57 & \multirow{2}{*}{1.485} & \multirow{2}{*}{0.151} \\
\hline & Control & 15 & 148.60 & 46.50 & & \\
\hline \multirow{2}{*}{$\begin{array}{l}60 \% \text { Left knee Flex. } \\
\text { Strength }(\mathrm{nm})\end{array}$} & Soccer & 15 & 94.73 & 10.65 & \multirow{2}{*}{0.838} & \multirow{2}{*}{0.414} \\
\hline & Control & 15 & 87.20 & 33.16 & & \\
\hline \multirow{2}{*}{$\begin{array}{l}\text { 180 Right knee Ext. } \\
\text { Strength }(\mathrm{nm})\end{array}$} & Soccer I & 15 & 106.60 & 25.12 & \multirow{2}{*}{1.070} & \multirow{2}{*}{0.295} \\
\hline & Control & 15 & 98.20 & 17.11 & & \\
\hline \multirow{2}{*}{$\begin{array}{l}\text { 180 Right knee Flex. } \\
\text { Strength }(\mathrm{nm})\end{array}$} & Soccer & 15 & 68.73 & 20.80 & \multirow{2}{*}{0.597} & \multirow{2}{*}{0.555} \\
\hline & Control & 15 & 64.27 & 20.17 & & \\
\hline \multirow{2}{*}{$\begin{array}{l}\text { 180 Left knee Ext. } \\
\text { Strength }(\mathrm{nm})\end{array}$} & Soccer & 15 & 101.93 & 21.34 & \multirow{2}{*}{1.097} & \multirow{2}{*}{0.282} \\
\hline & Control & 15 & 93.27 & 21.93 & & \\
\hline \multirow{2}{*}{$\begin{array}{l}\text { 180 Left knee Flex. } \\
\text { Strength }(\mathrm{nm})\end{array}$} & Soccer & 15 & 61.67 & 16.41 & \multirow{2}{*}{0.192} & \multirow{2}{*}{0.849} \\
\hline & Control & 15 & 60.60 & 13.84 & & \\
\hline \multirow{2}{*}{$\begin{array}{l}\text { 240 Right knee Ext. } \\
\text { Strength }(\mathrm{nm})\end{array}$} & Soccer & 15 & 88.07 & 17.84 & \multirow{2}{*}{1.262} & \multirow{2}{*}{0.218} \\
\hline & Control & 15 & 81.07 & 11.98 & & \\
\hline \multirow{2}{*}{$\begin{array}{l}240 \text { o Right knee Flex. } \\
\text { Strength }(\mathrm{nm})\end{array}$} & Soccer & 15 & 56.40 & 13.83 & \multirow{2}{*}{0.635} & \multirow{2}{*}{0.531} \\
\hline & Control & 15 & 53.00 & 15.46 & & \\
\hline \multirow{2}{*}{$\begin{array}{l}240 \text { Left knee Ext. } \\
\text { Strength (nm) }\end{array}$} & Soccer & 15 & 83.33 & 14.31 & \multirow{2}{*}{0.540} & \multirow{2}{*}{0.594} \\
\hline & Control & 15 & 80.27 & 16.71 & & \\
\hline $\begin{array}{l}240 \text { Left knee Flex. } \\
\text { Strength (nm) }\end{array}$ & Soccer & 15 & 49.47 & 10.15 & 0.018 & 0.985 \\
\hline & Control & 15 & 49.40 & 9.72 & & \\
\hline
\end{tabular}


Table 4. The association between descriptive parameters and isokinetic knee strength and agility

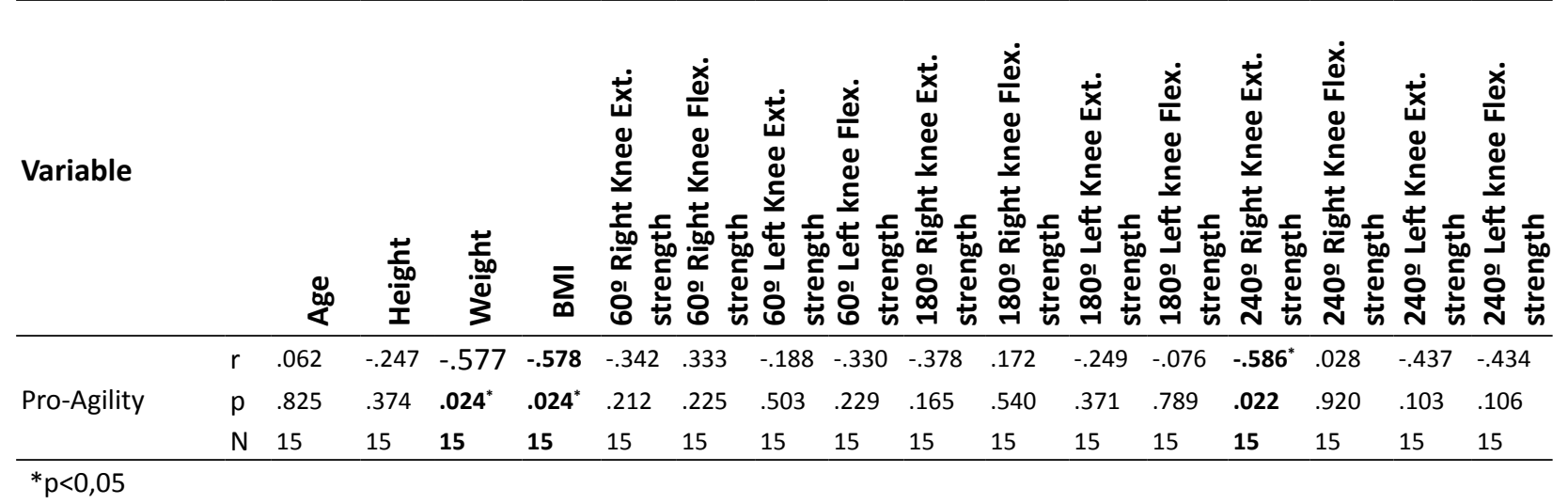

Table 5. Analysis of positions in terms of descriptive information, agility and isokinetic strength rates

\begin{tabular}{|c|c|c|c|c|c|c|c|}
\hline Variable & & $\mathbf{n}$ & Mean & SD & $\mathbf{F}$ & $\mathbf{P}$ & Significant difference \\
\hline \multirow{4}{*}{ Age (years) } & 1.Defender & 6 & 23.00 & 2.45 & \multirow{4}{*}{1.412} & \multirow{4}{*}{0,262} & \multirow{4}{*}{-} \\
\hline & 2.Midfielder & 5 & 23.20 & 1.64 & & & \\
\hline & 3.Forward & 4 & 22.00 & 2.58 & & & \\
\hline & 4.Control & 15 & 21.60 & 1.40 & & & \\
\hline \multirow{4}{*}{ Height (cm) } & 1.Defender & 6 & 179.67 & 3.44 & \multirow{4}{*}{2.106} & \multirow{4}{*}{0,124} & \multirow{4}{*}{-} \\
\hline & 2.Midfielder & 5 & 172.60 & 4.56 & & & \\
\hline & 3.Forward & 4 & 178.50 & 3.87 & & & \\
\hline & 4.Control & 15 & 175.73 & 5.81 & & & \\
\hline \multirow{4}{*}{ Weight (kg) } & 1.Defender & 6 & 80.53 & 6.73 & \multirow{4}{*}{4.589} & \multirow{4}{*}{0,010} & \multirow{4}{*}{$\begin{array}{l}2-1 \\
4-1\end{array}$} \\
\hline & 2.Midfielder & 5 & 70.84 & 2.69 & & & \\
\hline & 3.Forward & 4 & 75.45 & 7.18 & & & \\
\hline & 4.Control & 15 & 72.63 & 4.07 & & & \\
\hline \multirow{4}{*}{$\mathrm{BMI}\left(\mathrm{kg} / \mathrm{m}^{2}\right)$} & 1.Defender & 6 & 24.91 & 1.45 & \multirow{4}{*}{0.876} & \multirow{4}{*}{0,466} & \multirow{4}{*}{-} \\
\hline & 2.Midfielder & 5 & 23.80 & 1.28 & & & \\
\hline & 3.Forward & 4 & 23.68 & 2.19 & & & \\
\hline & 4.Control & 15 & 23.57 & 1.84 & & & \\
\hline \multirow{4}{*}{ Sports age (years) } & 1.Defender & 6 & 11.17 & 1.60 & \multirow{4}{*}{143.875} & \multirow{4}{*}{0,001} & \multirow{3}{*}{$\begin{array}{l}1-4 \\
2-4\end{array}$} \\
\hline & 2.Midfielder & 5 & 10.80 & 1.64 & & & \\
\hline & 3.Forward & 4 & 9.75 & 0.96 & & & \\
\hline & 4.Control & 15 & 2.93 & 0.26 & & & $3-4$ \\
\hline \multirow{4}{*}{ Pro Agility (sec) } & 1.Defender & 6 & 4.55 & 0.19 & \multirow{4}{*}{2.923} & \multirow{4}{*}{0,050} & \multirow{4}{*}{$1-4$} \\
\hline & 2.Midfielder & 5 & 4.78 & 0.14 & & & \\
\hline & 3.Forward & 4 & 4.80 & 0.27 & & & \\
\hline & 4.Control & 15 & 4.89 & 0.26 & & & \\
\hline \multirow{4}{*}{$\begin{array}{l}\text { Right extension } 60 \text { - } \\
(\mathrm{nm})\end{array}$} & 1.Defender & 6 & 185.83 & 55.05 & \multirow{4}{*}{3.768} & \multirow{4}{*}{0,023} & \\
\hline & 2.Midfielder & 5 & 122.60 & 15.81 & & & $1-2$ \\
\hline & 3.Forward & 4 & 147.00 & 31.23 & & & $4-2$ \\
\hline & 4.Control & 15 & 165.00 & 24.83 & & & \\
\hline & 1.Defender & 6 & 100.67 & 38.06 & & & \\
\hline Right flexion & 2.Midfielder & 5 & 84.60 & 9.50 & 1030 & 0396 & \\
\hline $60 \%(\mathrm{~nm})$ & 3.Forward & 4 & 99.25 & 25.60 & 1.030 & 0,590 & - \\
\hline & 4.Control & 15 & 105.60 & 17.70 & & & \\
\hline & 1.Defender & 6 & 179.33 & 41.25 & & & $1-2$ \\
\hline Left extension & 2.Midfielder & 5 & 134.60 & 35.22 & 3527 & 9כ0 ח & \\
\hline $60 \div(\mathrm{nm})$ & 3.Forward & 4 & 120.00 & 47.91 & 3.521 & $0,0<5$ & 10 \\
\hline & 4.Control & 15 & 169.73 & 29.57 & & & $4-2,4-3$ \\
\hline
\end{tabular}


Cont. Table 5

\begin{tabular}{|c|c|c|c|c|c|c|c|}
\hline Variable & & $\mathbf{n}$ & Mean & SD & $\mathbf{F}$ & $\mathbf{P}$ & Significant difference \\
\hline \multirow{4}{*}{$\begin{array}{l}\text { Left extension } \\
600(\mathrm{~nm})\end{array}$} & 1.Defender & 6 & 179.33 & 41.25 & \multirow{4}{*}{3.527} & \multirow{4}{*}{0,029} & \multirow{2}{*}{$1-2$} \\
\hline & 2.Midfielder & 5 & 134.60 & 35.22 & & & \\
\hline & 3.Forward & 4 & 120.00 & 47.91 & & & $1-3$ \\
\hline & 4.Control & 15 & 169.73 & 29.57 & & & $4-2,4-3$ \\
\hline \multirow{5}{*}{ Left flexion $60 \%(\mathrm{~nm})$} & 1.Defender & 6 & 110.33 & 35.76 & \multirow{4}{*}{5.076} & \multirow{4}{*}{0,007} & \\
\hline & 2.Midfielder & 5 & 79.40 & 19.71 & & & $1-2,1-3$ \\
\hline & 3.Forward & 4 & 62.25 & 21.93 & & & $4-3$ \\
\hline & 4.Control & 15 & 94.73 & 10.65 & & & \\
\hline & 1.Defender & 6 & 116.83 & 29.69 & \multirow{4}{*}{1.256} & \multirow{4}{*}{0,310} & \\
\hline \multirow{4}{*}{$\begin{array}{l}\text { Right extension } \\
180 \cong(\mathrm{nm})\end{array}$} & 2.Midfielder & 5 & 96.40 & 23.73 & & & \multirow{3}{*}{-} \\
\hline & 3.Forward & 4 & 104.00 & 18.28 & & & \\
\hline & 4.Control & 15 & 98.20 & 17.11 & & & \\
\hline & 1.Defender & 6 & 74.50 & 27.13 & \multirow{4}{*}{0.566} & \multirow{4}{*}{0,642} & \multirow{4}{*}{-} \\
\hline \multirow{4}{*}{$\begin{array}{l}\text { Right flexion } \\
1800(\mathrm{~nm})\end{array}$} & 2.Midfielder & 5 & 60.20 & 6.57 & & & \\
\hline & 3.Forward & 4 & 70.75 & 23.27 & & & \\
\hline & 4.Control & 15 & 64.27 & 20.17 & & & \\
\hline & 1.Defender & 6 & 103.00 & 25.67 & \multirow{4}{*}{1.090} & \multirow{4}{*}{0,371} & \multirow{4}{*}{-} \\
\hline \multirow{4}{*}{$\begin{array}{l}\text { Left extension } \\
180 \cong(\mathrm{nm})\end{array}$} & 2.Midfielder & 5 & 88.00 & 17.71 & & & \\
\hline & 3.Forward & 4 & 85.25 & 20.17 & & & \\
\hline & 4.Control & 15 & 101.93 & 21.34 & & & \\
\hline & 1.Defender & 6 & 66.17 & 17.60 & \multirow{4}{*}{0.549} & \multirow{4}{*}{0,653} & \multirow{4}{*}{-} \\
\hline \multirow{3}{*}{$\begin{array}{l}\text { Left flexion } \\
180=(\mathrm{nm})\end{array}$} & 2.Midfielder & 5 & 62.60 & 20.56 & & & \\
\hline & 3.Forward & 4 & 53.75 & 7.14 & & & \\
\hline & 4.Control & 15 & 60.60 & 13.84 & & & \\
\hline \multirow{3}{*}{$\begin{array}{l}\text { Right extension } \\
240 \text { o }\end{array}$} & 1.Defender & 6 & 95.17 & 20.84 & \multirow{4}{*}{1.300} & & \\
\hline & 2.Midfielder & 5 & 82.00 & 19.70 & & (205 & 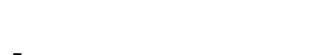 \\
\hline & 3.Forward & 4 & 85.00 & 8.37 & & 0,295 & - \\
\hline$(\mathrm{nm})$ & 4.Control & 15 & 81.07 & 11.98 & & & \\
\hline & 1.Defender & 6 & 61.33 & 21.01 & & & \\
\hline Right flexion & 2.Midfielder & 5 & 52.40 & 7.02 & 0504 & 0683 & - \\
\hline $2400(\mathrm{~nm})$ & 3.Forward & 4 & 54.00 & 2.94 & 0.304 & 0,003 & - \\
\hline & 4.Control & 15 & 53.00 & 15.46 & & & \\
\hline & 1.Defender & 6 & 88.50 & 18.43 & & & \\
\hline Right extension & 2.Midfielder & 5 & 80.60 & 15.49 & 1712 & 0189 & - \\
\hline $2400(\mathrm{~nm})$ & 3.Forward & 4 & 67.50 & 8.06 & 1.113 & 0,189 & - \\
\hline & 4.Control & 15 & 83.33 & 14.31 & & & \\
\hline & 1.Defender & 6 & 54.67 & 13.23 & & & \\
\hline Left flexion & 2.Midfielder & 5 & 47.00 & 4.90 & 1021 & 0399 & - \\
\hline $2400(\mathrm{~nm})$ & 3.Forward & 4 & 44.50 & 4.43 & 1.021 & 0,399 & - \\
\hline & 4.Control & 15 & 49.47 & 10.15 & & & \\
\hline
\end{tabular}

of soccer players playing in amateur leagues [24] and the third league [25]; however, they were found to be lower when compared with junior national team $[25,26]$ and professional soccer players $[27,28]$. In addition, in line with the results of our study, other studies have found the strength rate to decrease as angular speed increased. When the results are examined, it can be seen that as the quality of football leagues increase, strength rates give better results, and that training by top-level leagues should be programmed more systematically and scientifically than the lower leagues and the content should also be more systematic and scientific.

When the isokinetic knee strengths were compared in terms of positions, significant differences were determined between defenders and forwards and midfielders in $60^{\circ} \mathrm{sec}^{-1}$ right and left knee extension and $60^{\circ} \mathrm{sec}^{-1}$ left knee flexion strengths in favour of defenders ( $p<$ 0.05 ). No statistically difference was observed in other 
angular speeds $(p>0.05)$. According to the results of our study, when isokinetic knee strengths were examined according to positions, it was found that significant distinction decreased as angular speed increased. Other studies comparing isokinetic knee strength with respect to positions showed that defenders had higher strength rates than forwards and midfielders [7, 29]. Based on this, defenders showing higher rates than midfielders and forwards at lower angular speeds was thought to be the result of defenders having to move faster within the game to prevent the attacks by the opponent and, due to their sudden reactions at the moment of defence, they have more developed fast twitch muscle fibril structures [30].

When the agility times of soccer players and the control group were examined, a distinction was significantly found in favour of the soccer players $(p<0.05)$. However, when agility times were compared in terms of soccer players' positions, no distinction was found ( $\mathrm{p}>0.05)$. Agility times in our study and those in literature were found to be in parallel $[19,35]$. When the association between isokinetic knee strength and agility times were examined, a negative correlation was found only between $240^{\circ} \mathrm{sec}^{-1}$ right knee extension strength and agility $(\mathrm{p}<0.05)$. No significance was found in $60^{\circ} \mathrm{sec}^{-1}$ and $180^{\circ} \mathrm{sec}^{-1}$ angular speeds. When some studies that analysed the association between knee strength and agility were examined [31,32], it was found that the studies which did not find correlation between two parameters were found to be in parallel with our study. Another studies were examined, it was found that small correlation between two parameters [33, 34]. When the association between these two parameters was analysed, it was found that isokinetic knee strength did not have an influence on agility in low angular speeds [36] but had a positive influence on agility as angular speed increased [37, 38].

\section{Conclusion}

In summary, it was found that isokinetic strength rates in soccer players differed in terms of the quality of the league they played in, and amateur soccer players were found to have lower strength rates than those playing in national teams or those playing professionally. According to positions, it was found that defenders had better results than players in other positions in $60^{\circ} \mathrm{sec}^{-1}$ knee strengths. Besides, it was found that agility times of soccer players decreased as $240^{\circ} \mathrm{sec}^{-1}$ right knee extension strength increased; however, no correlation was found between positions.

\section{Acknowledgements}

This study was written by abridging Ali Kerim YILMAZ's Ondokuz Mayıs University Institute of Health Sciences, Physical Training and Sports Department master's thesis. No grants or financial aids were taken in this Project.

\section{Financial support}

There is no financial support.

\section{Conflict of interest}

The authors declare no conflict of interest.

\section{References}

1. Cometti G, Maffiuletti NA, Pousson M, Chatard JC, Maffulli N. Isokinetic strength and anaerobic power of elite, subelite and amateur French soccer players. International journal of sports medicine, 2001; 22(01): 45- 51. https://doi.org/10.1055/s-2001-11331

2. Little T, Alun GW. Specificity of acceleration, maximum speed, and agility in professional soccer players. The Journal of Strength \& Conditioning Research, 2005; 19(1): 76- 78. https://doi.org/10.1519/00124278-200502000-00013

3. Jovanovic M, Sporis G, Omrcen D, Fiorentini F. Effects of speed, agility, quickness training method on power performance in elite soccer players. The Journal of Strength \& Conditioning Research, 2011; 25(5): 1285- 1292. https://doi.org/10.1519/JSC.0b013e3181d67c65

4. Mathieu R, Ferret JM, Moyen B, Rebourg JF Seller M. Protocole de mesure des amplitudes articulaires des membres inferieurs du footballeur, Act Sport et Med 1992; 15-19.

5. Bangsbo J, Nørregaard L, Thorsø F. Active profile of competition soccer, Can J Sports Sci, 1991; 16:110-116.

6. Levanon J, Dapena J. Comparison of the kinetics of the full-instep and pass kicks in soccer, Med Sci Sports Exerc, 1998; 30:917- 927. https://doi.org/10.1249/00005768-199806000-00022

7. Tourny-Chollet $\mathrm{C}$, Leroy D, Beuret-Blanquart F. Isokinetic knee muscle strength of soccer players according to their position. Isokinetics and exercisescience, 2000; 8(4): 187-193. https://doi.org/10.3233/IES-2000-0050

8. Sheppard JM, Warren BY. Agility literature review: Classifications, training and testing. Journal of sports sciences 2006; 24(9): 919- 932. https://doi.org/10.1080/02640410500457109

9. Little T, Alun GW. Effects of differential stretching protocols during warm-ups on high-speed motor capacities in professional soccer players. The Journal of Strength \& Conditioning Research 2006; 20(1): 203- 307. https://doi.org/10.1519/00124278-200602000-00033

10.Malliou P, Ispirlidis I, Beneka A, Taxildaris K, Godolias G. Vertical jump and knee extensors isokinetic performance in professional soccer players related to the phase of the training period. Isokinetics and exercise science, 2003; 11(3): 165-169. https://doi.org/10.3233/IES-2003-0144

11.Lees A, Nolan L. The biomechanics of soccer: A review, $J$ Sports Sci, 1998; 19: 211- 234. https://doi.org/10.1080/026404198366740

12.Agre J, Baxter TL, Musculoskeletal profile of male collegiate soccer players, Arch Phys Med Rehabil, 1987; (68):147- 150.

13.Taşmektepligil MA. The Relationship between Balance Performance and KneeFlexor-Extensor Muscular Strength of Football Players. Anthropologist, 2016; 23(3): 398- 405. https://doi.org/10.1080/09720073.2014.11891960

14.Zakas KM, Vamvakoudis K, Christoulas E, Aggelopoulou $\mathrm{N}$. Peak torque of quadriceps and hamstrings muscles in basketball and soccer players of different divisions, $J$ Sports Med Phys Fitness 1995; 35:199-205.

15. Gur H, Akova Z, Punduk Z, Kucukoglu S, Effects of age on the reciprocal peak torque ratios during knee muscles contractions in elite soccer players, Scand J Med Sci ,1999; 9:81- 87. 
https://doi.org/10.1111/j.1600-0838.1999.tb00213.x

16.Rochcongar P, Morvan R, Dasonville JJ, Beillot J. Isokinetic investigation of knee extensors and knee flexors in young French soccer players, Int J Sports Med 1988; 9: 448- 450. https://doi.org/10.1055/s-2007-1025049

17.Capranica L, Cama G, Fanton A, Tessitore A, Figura F. Force and power of preferred and non-preferred leg in young soccer players, J Sports Med Phys Fitness, 1992; 31: 358-363.

18.Newman MA, Tarpenning KM, Marino FE. Relationships between isokinetic knee strength, single-sprint performance, and repeated-sprint ability in football players. The Journal of Strength \& Conditioning Research, 2004;18(4): 867- 872. https://doi.org/10.1519/00124278-200411000-00032

19.Sierer SP, Battaglini CL, Mihalik JP, Shields EW, Tomasini NT. The National Football League Combine: performance differences between drafted and nondrafted players entering the 2004 and 2005 drafts. The Journal of Strength \& Conditioning Research, 2008; 22(1): 6- 12. https://doi.org/10.1519/JSC.0b013e31815ef90c

20.Alter MJ. Science of Stretching. Champaign, IL: Human Kinetics Pub.; 1988.

21.Davies MJ, Dalsky GP. Normalizing strength for body size differences in older adults. Medicine and Science in Sports and Exercise. 1997;29(5):713- 717. https://doi.org/10.1097/00005768-199705000-00020

22.Brochu M. Effects of resistance training on physical function in older disabled women with coronary heart disease. Journal of applied physiology , 2002; 92(2): 672- 678. https://doi.org/10.1152/japplphysiol.00804.2001

23.De Proft E, Clarys JP, Bollens E, Cabri J, Dufour W. Muscle activity in the soccer kick. Science and football. London: E \& FN Spon; 1988.

24.Öberg B, Möller M, Gillquist J, Ekstrand J. Isokinetic torque levels for knee extensors and knee flexors in soccer players. International journal of sports medicine, 1986; 7(01): 50- 53. https://doi.org/10.1055/s-2008-1025735

25.Aginsky JD, Neophytou N, Charalambous T. Isokinetic hamstring andquadricepsmusclestrength profiles of elite South African football players. African Journal for Physical, Health Education, Recreation and Dance, 2014; 20(3-2): 1225- 1575. https://doi.org/10.1080/00140130500101585

26.Rahnam, N, Lees A, Bambaecichi E. A comparison of muscle strength and flexibility between the preferred and nonpreferred leg in English soccer players. Ergonomics, 2005; 48(11-14): 1568-1575.

27.Masuda K, Kikuhara N, Demura S, Katsuta S, Yamanaka K. Relationship between muscle strength in various isokinetic movements and kick performance among soccer players. Journal of Sports Medicine and Physical Fitness, 2005;45(1): 44

28.Aktuğ ZB, Harbili E, Harbili S Comparison of Isokinetic Knee Strength Between the Dominant and Non-dominant
Legs and Relationships Among Isokinetic Strength, Vertical Jump, and Speed Performance in Soccer Players. Turkiye Klinikleri Journal of Sports Sciences, 2016; 8(1): 8- 14. https://doi.org/10.5336/sportsci.2015-47409

29. Meriç B, Aydın M, Çolak T, Çolak E, Son M. The comparison of knee isokinetic performances and anthropometric measurement of professional soccers who play different position. Journal of Human Sciences, 2007; 4(2):10-16.

30. Yeefun S, Sirirat H, Chentanz T. Hamstring to quadriceps strength ratio in Mahidol University soccer players. $J$ Health Sci , 2002; 11: 201-209.

31.Thomas K, French D, Hayes PR. The effect of two plyometric training techniques on muscular power and agility in youth soccer players. The Journal of Strength \& Conditioning Research, 2009; 23(1): 332- 335. https://doi.org/10.1519/JSC.0b013e318183a01a

32.Çelenk Ç, Marangoz İ, Aktuğ ZB, Top E, Akıl M. The effect of quadriceps femoris and hamstring muscular force on static and dynamic balance performance. International Journal of Physical Education Sports and Health, 2015; 2(2): 323-325.

33. Young W, Farrow D. A Review of Agility: Practical Applications for Strength and Conditioning. Strength \& Conditioning Journal, 2006; 28(5): 24- 29. https://doi.org/10.1519/00126548-200610000-00004

34. Young W, Hawken M, McDonald L. Relationship between speed, agility and strength qualities in Australian Rules football. Strength Cond Coach, 1996; 4(4): 3-6.

35.Delextrat A, Cohen D. Strength, power, speed, and agility of women basketball players according to playing position. Journal of Strength and Conditioning Research, 2009; 23(7): 1974- 1981. https://doi.org/10.1519/JSC.0b013e3181b86a7e

36.Paoule K, Madole K, Garhammer J, Lacourse M, Rozenek R. Reliability and validity of the t-test as a measure of agility, leg power, and leg speed in college-aged men and women. Journal of Strength and Conditioning Research, 2000; 14: 443 - 450. https://doi.org/10.1519/00124278-200011000-00012

37.Patterson S, Udermann B, Doberstein S, Reineke D. The effects of cold whirlpool on power, speed, agility, and range of motion. Journal of Sports Science and Medicine, 2008;7: 387-394.

38.Erculj F, Blas M, Bracic M. Physical demands on young elite European female basketball players with special reference to speed, agility, explosive strength, and take-off power. J Strength Cond Res, 2010; 24(11): 2970- 2978. https://doi.org/10.1519/JSC.0b013e3181e38107

39.Alemdaroğlu U. The relationship between muscle strength, anaerobic performance, agility, sprint ability and vertical jump performance in professional basketball players. Journal of human kinetics, 2012; 31: 149- 158. https://doi.org/10.2478/v10078-012-0016-6 


\section{Information about the authors:}

Yılmaz A.K.; (Corresponding author); https://orcid.org/0000-0002-0046-6711; akerim.yilmaz@omu.edu.tr; Faculty of Sports Sciences, Ondokuz Mayıs University; Ondokuz Mayıs University Kurupelit Campus, 55139 Atakum/Samsun, Turkey:

Kabadayı M.; https://orcid.org/0000-0002-4472-7485; menderes@omu.edu.tr; Faculty of Sports Sciences, Ondokuz Mayıs University; Ondokuz Mayıs University Kurupelit Campus, 55139 Atakum/Samsun, Turkey:

Bostancı Ö.; https://orcid.org/0000-0002-7952-1014; bostanci@omu.edu.tr; Faculty of Sports Sciences, Ondokuz Mayıs University; Ondokuz Mayıs University Kurupelit Campus, 55139 Atakum/Samsun, Turkey:

Özdal M.; https://orcid.org/0000-0002-0286-2128; ozdalm@hotmail.com; Gaziantep University,Physical Education and Sport; Gaziantep University,Physical Education and Sport, 27350, Gaziantep, Turkey.

Mayda M.H.; https://orcid.org/0000-0002-7062-3284; hakan.mayda@omu.edu.tr; Faculty of Sports Sciences, Ondokuz Mayıs University; Ondokuz Mayıs University Kurupelit Campus, 55139 Atakum/Samsun, Turkey.

\section{Cite this article as:}

Yılmaz AK, Kabadayı M, Bostancı Ö, Özdal M, Mayda MH. Analysis of isokinetic knee strength in soccer players in terms of selected parameters. Physical education of students, 2019;23(4):209-216. https://doi.org/10.15561/20755279.2019.0408

This is an Open Access article distributed under the terms of the Creative Commons Attribution License, which permits unrestricted use, distribution, and reproduction in any medium, provided the original work is properly cited http://creativecommons.org/licenses/by/4.0/deed.en

Received: 04.07.2019

Accepted: 30.07.2019; Published: 28.08.2019 